\title{
Pengembangan Interoperabilitas Sistem Penaggulangan Gawat Darurat Terpadu (SPGDT) Kabupaten Kebumen
}

\author{
Dian Budi Santoso ${ }^{1}$, Angga Eko Pramono ${ }^{2}$, Agasi Gilang Persada ${ }^{3}$ \\ ${ }^{1,2}$ Sekolah Vokasi Universitas Gadjah Mada, ${ }^{3}$ Universitas Amikom Yogyakarta \\ dianbudisantoso@ugm.ac.id, anggaekopramono@ugm.ac.id, agasigp@live.com
}

\begin{abstract}
The Integrated Emergency Response System (SPGDT) is a web-based system that provides information about the availability of beds in hospitals and health centers inpatient care in Kebumen District. During this time the operators that are medical record officers in each hospital or health center input data manually into SPGDT so that data is not always updated regularly and not realtime. This study aims to develop interoperability of SPGDT so that data synchronization can be done automatically from the Hospital Management Information System (SIMRS) and the Health Center Management Information System (SIMPUS). This type of research is research and development. Needs asessment was carried out with focus group discussions (FGD) involving representatives from hospitals, inpatient health centers, health offices, and the Kebumen District Communication and Information Agency. A web service infrastructure has been developed in the form of an Application Programming Interface (API) that can be used by hospitals and health centers to synchronize data from SIMRS and SIMPUS automatically.
\end{abstract}

Keywords: SPGDT, interoperability, web service, application programming interface

\begin{abstract}
Abstrak
Sistem Penanggulangan Gawat Darurat Terpadu (SPGDT) adalah sistem berbasis web yang memberikan informasi tentang ketersediaan tempat tidur di rumah sakit maupun puskesmas rawat inap di Kabupaten Kebumen. Selama ini operator yaitu petugas rekam medis di masing-masing rumah sakit atau puskesmas menginputkan data secara manual ke SPGDT sehingga data tidak selalu ter-update secara rutin dan tidak realtime. Penelitian ini bertujuan mengembangkan interoperabilitas SPGDT sehingga dapat dilakukan sinkronisasi data secara otomatis dari Sistem Informasi Manajemen Rumah Sakit (SIMRS) dan Sistem Informasi Manajemen Puskesmas (SIMPUS). Jenis penelitian ini adalah research and development. Analisis kebutuhan dilakukan dengan focus group discussion (FGD) yang melibatkan perwakilan dari rumah sakit, puskesmas rawat inap, Dinas Kesehatan, serta Dinas Komunikasi dan Informatika Kabupaten Kebumen. Sebuah infrastruktur web service telah dikembangkan dalam bentuk Application Programming Interface (API) yang dapat digunakan oleh rumah sakit dan puskesmas untuk mensinkronkan data dari SIMRS dan SIMPUS secara otomatis.
\end{abstract}

Kata Kunci: SPGDT, interoperabilitas, web service, application programming interface

\section{Pendahuluan}

Penggunaan teknologi informasi pada bidang kesehatan memiliki potensi untuk meningkatkan kualitas pelayanan kesehatan dan keterlibatan yang lebih besar dari pasien dalam perawatan kesehatan mereka sendiri (Buntin et al, 2011). Saat ini penggunaan sistem berbasis teknologi informasi telah menjadi sebuah kebutuhan pokok terkait dengan pengumpulan, pengolahan, dan penyajian informasi kesehatan. Kualitas informasi yang disajikan menjadi salah satu indikator kualitas pelayanan di sebuah sarana pelayanan kesehatan (Ratnaningtyas \& Surendro, 2013).

Pada era jaminan kesehatan nasional, pelayanan kesehatan dilaksanakan secara berjenjang dimulai dari fasilitas kesehatan tingkat pertama seperti Puskesmas, Klinik Pratama, dan Dokter Keluarga. Pasien yang terdaftar sebagai anggota BPJS (Badan Penyelenggara Jaminan Sosial) hanya dapat dilayani di fasilitas kesehatan tingkat lanjut jika ada surat rujukan dari fasilitas kesehatan tingkat pertama 
kecuali dalam keadaan gawat darurat, kekhususan permasalahan kesehatan pasien, pertimbangan geografis, dan pertimbangan ketersedian fasilitas (Bitjoli \& Kusuma, 2015).

Pada keadaan darurat, fasilitas kesehatan harus dapat merujuk pasien dengan tepat sesuai dengan pertimbangan kebutuhan sarana prasarana dan dokter spesialis yang berkompeten menangani pasien. Hal yang menjadi permasalahan dalam sistem rujukan saat ini adalah fasilitas kesehatan sering terkendala dengan kurangnya informasi terkait ketersediaan tempat tidur atau kamar rawat inap di tempat tujuan rujukan sehingga seringkali pasien harus menunggu lama atau ditolak di tempat tujuan rujukan tersebut. Untuk menanggulangi hal tersebut, Kabupaten Kebumen telah meluncurkan Sistem Penanggulangan Gawat Darurat Terpadu (SPGDT) berbasis web yang berisi informasi tentang ketersediaan tempat tidur di rumah sakit dan puskesmas rawat inap. SPGDT di Kabupaten Kebumen telah diluncurkan sejak tahun 2016 dan digunakan sebagai acuan tenaga kesehatan dalam merujuk pasien.

Selama ini informasi di SPGDT diinputkan secara manual dan di-update setiap hari oleh operator yaitu petugas rekam medis di masing-masing rumah sakit dan puskesmas. Kebaruan informasi di SPGDT tergantung pada komitmen dan konsistensi dari para operator dalam melakukan pembaruan data. Beberapa rumah sakit di Kabupaten Kebumen telah menggunakan Sistem Informasi Manajemen Rumah Sakit (SIMRS) berbasis elektronik begitu juga puskesmas yang telah menggunakan Sistem Informasi Manajemen Puskesmas (SIMPUS) berbasis elektronik. Informasi ketersediaan tempat tidur rawat inap sebenarnya sudah ada pada SIMRS maupun SIMPUS dan selalu diperbarui seiring dengan transaksi data yang berlangsung di rumah sakit maupun puskesmas.

Salah satu kendala yang dihadapi dalam implementasi sistem informasi kesehatan berbasis elektronik adalah terkait interoperabilitas sistem. Sistem informasi kesehatan dibangun secara parsial dan tidak mampu berkomunikasi satu sama lain sehingga menyebabkan terjadinya double entry untuk beberapa data tertentu. Perlu dilakukan integrasi antar sistem dengan konsep pengembangan interoperabilitas sistem (Varga et al, 2016). Saat ini SPGDT tidak memiliki interoperabilitas dengan SIMRS dan SIMPUS. Diperlukan sebuah infrastruktur web service sehingga data pada SIMRS dan SIMPUS dapat tersinkron secara otomatis dengan data pada SPGDT.

\section{Metode}

Jenis penelitian ini adalah research and development. Penelitian dan pengembangan interoperabilitas SPGDT mengadopsi System Life Cycle Methodologies yang terdiri dari perencanaan, analisis kebutuhan, perancangan, implementasi, dan penggunaan (Mcleod \& Schell, 2007). Analisis kebutuhan dilakukan dengan focus group discussion (FGD) yang melibatkan perwakilan dari dari rumah sakit, puskesmas rawat inap, Dinas Kesehatan, serta Dinas Perhubungan, Komunikasi, dan Informatika Kabupaten Kebumen. Perancangan menggunakan Microsoft Office Visio 2016, implementasi menggunakan bahasa pemrograman PHP, XML, serta aplikasi POSTMAN dan Google Chrome. Uji coba penggunaan dilakukan oleh tim teknologi informasi RSUD Dr. Soedirman Kabupaten Kebumen.

\section{Hasil dan Pembahasan}

Perencanaan pengembangan interoperabilitas SPGDT Kabupaten Kebumen didasarkan pada masukan dari operator di rumah sakit yang telah memiliki SIMRS agar data dari SIMRS dapat langsung ter-update ke SPGDT secara otomatis tanpa harus diinput oleh operator secara manual. Dari hasil analisis kebutuhan diketahui bahwa SPGDT di-update oleh operator di rumah sakit dan puskesmas rawat inap setiap 3 jam. Data yang di-update meliputi data dokter jaga, dokter spesialis, ketersediaan kamar rwat inap, kantong darah, dan ventilator. Dalam prakteknya tidak semua operator meng-update data secara periodik. Sering terjadi keterlambatan update data sehingga informasi yang ditampilkan dalam website SPGDT tidak sesuai dengan kondisi sebenarnya. Operator yang menggunakan SIMRS dan SIMPUS juga harus melakukan double entry data jika ada pasien masuk atau pulang rawat inap. Data pasien rawat inap harus diinput dua kali ke SIMRS/SIMPUS dan SPGDT, hal ini tentu menambah beban kerja operator. Data pada SPGDT diharapkan dapat ter-update secara otomatis seiring dengan update data pasien rawat inap pada SIMRS/SIMPUS. Untuk memfasilitasi hal tersebut, dikembangkan Application Programming Interface (API) yang memfasilitasi interoperabilitas data antara SPGDT dengan SIMRS dan SIMPUS. 
Dian Budi Santoso, Angga Eko Pramono, Agasi Gilang Persada. Pengembangan Interoperabilitas ....

Rancangan interoperabiltas antara SPGDT dengan SIMRS dan SIMPUS dapat dilihat pada Gambar 1. Ketika operator menginputkan data pada SIMRS dan SIMPUS maka data yang diinputkan tersebut juga otomatis akan meng-update data yang ada pada SPGDT sehingga operator tidak perlu menginputkan data yang sama dua kali.

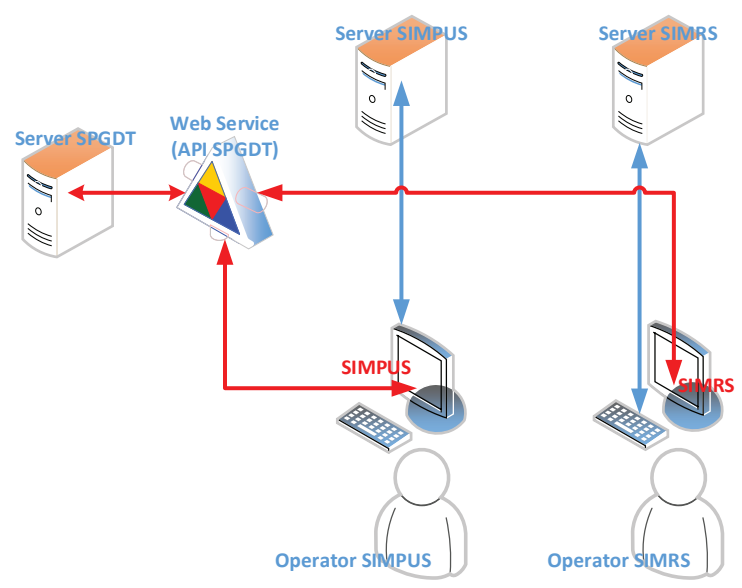

Gambar 1. Rancangan interoperabilitas antara SPGDT dengan SIMPUS dan SIMRS

API adalah antarmuka yang sederhana, fleksibel, dan efisien untuk melakukan query atau berinteraksi dengan basis data sebuah sitem berbasis pola Representational State Transfer (REST) untuk web (Ong et al, 2015). API seperti sebuah alamat web yang dibuat untuk memproses request yang diterima dengan parameter tertentu (Dharani, 2018). Semua aturan dalam penggunaanya ditentukan oleh programmer yang membuatnya dan didokumentasikan dalam bentuk katalog (Jacobson et al, 2012).

Sebelum API dibuat, terlebih dahulu source code SPGDT yang disimpan pada server Dinas Perhubungan, Komunikasi, dan Informatika Kabupaten Kebumen dipelajari dan dianalisis. Source code SPGDT Kabupaten Kebumen bersifat open source atau kode terbuka sehingga dapat diakses dan dipelajari dengan bebas untuk pengembangan berikutnya. Sebuah software dikatakan open source jika bebas untuk digunakan, diinvestigasi, dimodifikasi dan didistribusikan dengan atau tanpa perubahan (Joia \& Vinhais, 2017). Dari hasil analisis diketahui bahwa SPGDT dibangun menggunakan Laravel PHP framework dan database MySQL. Laravel adalah salah satu PHP framework yang sedang populer saat ini (Samra, 2015). Tren penggunaan Laravel di seluruh dunia juga semakin meningkat seiring dengan berbagai fungsionalitas yang terus ditambahkan oleh pengembangnya (Amanatidis \& Chatzigeorgiou, 2016). Dokumentasi tentang cara penggunaannya juga dapat ditemukan dengan mudah di internet sehingga mudah untuk dipelajari.

Selanjutnya API SPGDT dikembangkan menggunakan Laravel mengikuti pengembang SPGDT sebelumnya. Ujicoba dalam proses pengembangannya menggunakan Google Chrome dan aplikasi POSTMAN untuk menguji apakah API yang dibuat sudah dapat digunakan (Darmadi et al, 2018).

API yang sudah dibuat kemudian dipublikasikan dalam bentuk katalog yang dapat diakses melalui alamat https://spgdt-doc.agasigp.web.id/. API yang dibuat memuat fasilitas update untuk setiap item informasi yang ada pada SPGDT. Alamat API untuk proses update data dapat dilihat pada Tabel 1.

Tabel 1. Fasilitas update data pada katalog API SPGDT

\begin{tabular}{|c|c|c|}
\hline No & Aksi & Alamat \\
\hline 1 & Update dokter jaga & $\begin{array}{l}\text { http://spgdt.kebumenkab. } \\
\text { go.id/api/dokter }\end{array}$ \\
\hline 2 & $\begin{array}{l}\text { Update dokter } \\
\text { spesialis }\end{array}$ & $\begin{array}{l}\text { http://spgdt.kebumenkab. } \\
\text { go.id/api/dokter/spesialis }\end{array}$ \\
\hline 3 & $\begin{array}{l}\text { Update kamar } \\
\text { Kelas } 1\end{array}$ & $\begin{array}{l}\text { http://spgdt.kebumenkab. } \\
\text { go.id/api/kamar/kelas1 }\end{array}$ \\
\hline 4 & $\begin{array}{l}\text { Update kamar } \\
\text { Kelas } 2\end{array}$ & $\begin{array}{l}\text { http://spgdt.kebumenkab. } \\
\text { go.id/api/kamar/kelas2 }\end{array}$ \\
\hline 5 & $\begin{array}{l}\text { Update kamar } \\
\text { Kelas } 3\end{array}$ & $\begin{array}{l}\text { http://spgdt.kebumenkab. } \\
\text { go.id/api/kamar/kelas3 }\end{array}$ \\
\hline 6 & Update kamar VIP & $\begin{array}{l}\text { http://spgdt.kebumenkab. } \\
\text { go.id/api/kamar/vip }\end{array}$ \\
\hline 7 & $\begin{array}{l}\text { Update kamar } \\
\text { VVIP }\end{array}$ & $\begin{array}{l}\text { http://spgdt.kebumenkab. } \\
\text { go.id/api/kamar/vvip }\end{array}$ \\
\hline 8 & $\begin{array}{l}\text { Update kamar } \\
\text { UGD }\end{array}$ & $\begin{array}{l}\text { http://spgdt.kebumenkab. } \\
\text { go.id/api/kamar/ugd }\end{array}$ \\
\hline 9 & Update kamar ICU & $\begin{array}{l}\text { http://spgdt.kebumenkab. } \\
\text { go.id/api/kamar/icu }\end{array}$ \\
\hline
\end{tabular}


10 Update kamar ICCU

11 Update kantong darah

12 Update ventilator http://spgdt.kebumenkab. go.id/api/kamar/iccu

http://spgdt.kebumenkab. go.id/api/kantong-darah

http://spgdt.kebumenkab. go.id/api/kamar/ ventilator

Untuk dapat berkomunikasi dengan SPGDT melalui alamat di atas, pengembang SIMRS harus mendapatkan token autentikasi terlebih dahulu menggunakan username dan password yang biasa digunakan operator untuk login ke dalam sistem. Jika username dan password yang dimasukkan benar maka akan muncul respon dari API SPGDT berupa token yang dapat digunakan sebagai autentikasi saat melakukan komunikasi data.

Setelah proses autentikasi berhasil, SIMRS dapat langsung mengirimkan data secara otomatis dan berkala ke server SPGDT sehingga operator rumah sakit tidak perlu lagi menginputkan data secara manual. Teknologi yang digunakan dalam proses ini adalah web service. Teknologi web service dikenal

sebagai layanan yang disediakan oleh pengembang sebuah sistem agar dapat berkomunikasi dengan sistem lain melalui protokol dan bahasa tertentu (Zhou et al, 2018). Konsep implementasi teknologi web service adalah adanya interaksi antara servce provider dan service requester (Kreger, 2003). Dalam hal ini service provider adalah SPGDT dan service requester adalah rumah sakit atau puskesmas yang akan menggunakan API.

Setelah dipublikasikan, API SPGDT dapat digunakan oleh tim pengembang SIMRS dan SIMPUS untuk mengintegrasikan sistem yang mereka kembangkan dengan SPGDT. Uji coba penggunaan yang pertama dilakukan oleh tim teknologi informasi RSUD Dr. Soedirman Kabupaten Kebumen. Setelah API SPGDT digunakan dan diintegrasikan dengan SIMRS, data ketersediaan tempat tidur pada RSUD Dr. Soedirman dapat di-update secara realtime tanpa harus menginputkan data secara manual. Pada Gambar 2 dapat dilihat bahwa data RSUD Dr. Soedirman di-update terakhir satu detik yang lalu yang menunjukkan bahwa data pada SPGDT sudah tersinkronisasi secara otomatis dengan data pada SIMRS RSUD Dr. Soedirman.

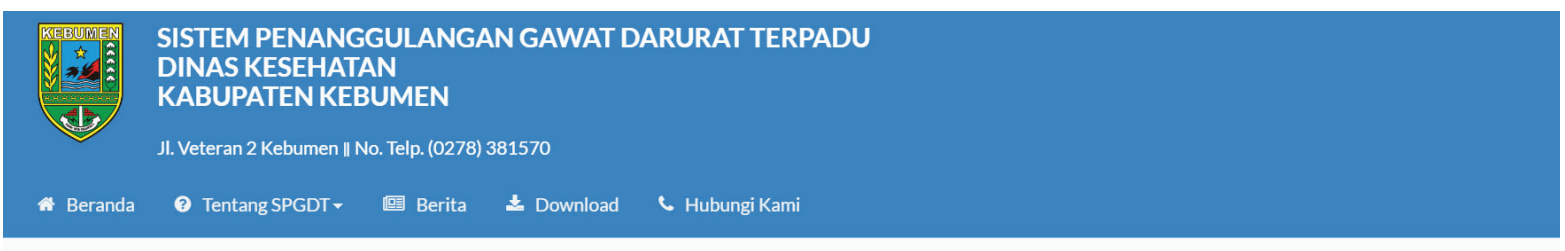

- Selamat Datang di Sistem Penanggulangan Gawat Darurat Terpadu Kabupaten Kebumen.

\section{HJUMLAHTEMPAT TIDUR TERSEDIA RUMAH SAKIT}

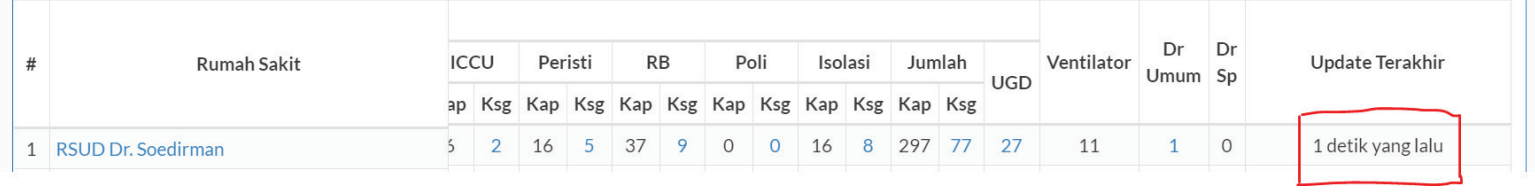

Gambar 2. Screenshot informasi pada SPGDT Kabupaten Kebumen yang telah di-update secara otomatis dan realtime

Operator SPGDT di RSUD Dr. Soedirman dalam hal ini adalah petugas rekam medis merasa sangat terbantu dengan pengembangan interoperabilitas SPGDT. Petugas tidak perlu lagi menginput data dua kali pada SIMRS dan SPGDT.
Dalam beberapa dekade terakhir beberapa negara berinisiatif mengembangkan interoperabilitas sistem informasi kesehatan namun menghadapi beberapa kendala diantaranya adalah tidak adanya standar pertukaran informasi, tidak adanya model bisnis sistem informasi kesehatan yang berkelanjutan, serta 
Dian Budi Santoso, Angga Eko Pramono, Agasi Gilang Persada. Pengembangan Interoperabilitas ....

resiko investasi yang tinggi (Zhang et al, 2017). Pengembangan interoperabilitas SPGDT di Kabupaten Kebumen ini menunjukkan bahwa sebenarnya komunikasi data antar sistem informasi kesehatan bisa dengan mudah dilakukan jika semua pihak terkait sepakat dan memiliki komitmen untuk mewujudkannya.

\section{Simpulan}

Telah dikembangkan interoperabalitas SPGDT Kabupaten Kebumen dengan memanfaatkan teknologi web service. SPGDT menyediakan API yang katalognya dapat diakses secara online. Dengan teknologi ini maka rumah sakit dan puskesmas rawat inap dapat mengirimkan data secara otomatis dan berkala ke server SPGDT sehingga operator tidak perlu lagi menginputkan data secara manual.

\section{Daftar Pustaka}

Amanatidis, T., Chatzigeorgiou, A. (2016). Studying the evolution of PHP web applications. Information and Software Technology, 72, 48-67.

Bitjoli, D. \& Kusuma, A. P., (2015). Gambaran Pelaksanaan Rujukan Lanjut Berjenjang Pada Pasien BPJS di Puskesmas Ngesrep Kota Semarang Tahun 2015. Universitas Dian Nuswantoro. Semarang: Fakultas Kesehatan.

Buntin, M. B., Burke, M. F., Hoaglin, M. C., Blumenthal, D. (2011). The Benefits Of Health Information Technology: A Review Of The Recent Literature Shows Predominantly Positive Results. Health Aafirs, 30(3), 464471.

Darmadi, H., Liawatimena, S., Abbas, B. S., Trisetyarso, A. (2018). Hypermedia Driven Application Programming Interface for Learning Object Management. 3rd International Conference on Computer Science and Computational Intelligence. Procedia Computer Science, 135, 120-127.

Dharani, R. (2018). WEB API Design: WEB Application Programming Interface Design. Independently Published.
Jacobson, D., Brail, G., Woods, D. (2012). APIs: A Strategy Guide. California: Evolved Media.

Joia, L. A., Vinhasi, J. C. D. S. (2017). From closed source to open source software: Analysis of the migration process to Open Office. The Journal of High Technology Management Research, 28(2), 261-272.

Kreger, H. (2003). Fulfilling The Web Services Promise. Communication of the ACM, 46(6), 29-34.

McLeod, R., Schell, G. (2007). Management Information System (10 ${ }^{\text {th }}$ Edition). New Jersey: Prentice Hall.

Ong, P. S., Cholia, S., Jain, A., Brafman, M., Gunter, D., Ceder, G., Persson, K. A. (2015). The Materials Application Programming Interface (API): A simple, flexible and efficient API for materials data based on REpresentational State Transfer (REST) principles. Computational Materials Science, 97, 209-215.

Ratnaningtyas, D. D., \& Surendro, K. (2013). Information Quality Improvement Model on Hospital Information System using Six Sigma. Procedia Technology, 9, 1166-1172.

Samra, J. (2015). Comparing Performance of Plain PHP and Four of Its Popular Framework. Kalmar: Linnaeus University.

Varga, P., Blomstedt, F., Ferreira, L. L., Eliasson, J., Johansson, M., Delsing, J., Soria, I. M. (2016). Making system of systems interoperable - The core components of the Arrowhead framework. Journal of Network and Computer Applications, 81, 85-95.

Zhang, H., Han., B, T., Tang, Z. (2017). Constructing a nationwide interoperable health information system in China: The case study of Sichuan Province. Health Policy and Technology, 6(2), 142-151.

Zhou, B., Zhang, Q., Shi, Q., Yang, Q., Yang, P., Yu, Y. (2018). Measuring web service security in the era of Internet of Things. Computers \& Electrical Engineering, 66, 305-315. 